\title{
Los estándares de prueba y el boom editorial del discurso probatorio en castellano
}

\author{
The Standards of Proof and the Editorial Boom \\ of the Evidence Discourse in Spanish
}

\section{Claudio Agüero San Juan*}

Si alguna vez la claridad, la ciencia, la belleza abrian sus ventanas, era permitido gozar, entre muros de libros, la exquisita paz de la mansión de un letrado.

Robert Musil El hombre sin atributos

(1942: 14-15)

Recepción y evaluación de propuesta: 15/04/2016

Aceptación: 15/7/2016

Recepción y aceptación final: 4/7/2017

Resumen: Formulo un comentario al artículo "Los usos de los estándares de prueba" de Rodrigo Coloma. Resulta problemática la propuesta de entender el estándar de prueba como umbral porque no hay una magnitud mensurable. La fragilidad conceptual del discurso probatorio impide hacer más observaciones a la propuesta. Ante esta fragilidad la mejor opción es el silencio. Luego, resulta interesante observar la difusión de las investigaciones de prueba como un boom editorial de un discurso especializado.

Palabras clave: estándares de prueba, boom editorial, discurso probatorio

* Profesor de la Facultad de Derecho de la Universidad Alberto Hurtado.

Correo electrónico: aguero.claudio@gmail.com 


\begin{abstract}
I comment on the article "The uses of the standards of proof" by Rodrigo Coloma. The proposal to understand the test standard as threshold is problematic because there is no measurable magnitude. The conceptual fragility of the probative discourse prevents further observations on the proposal. Before this fragility the best option is the silence. Then, it is interesting to observe the diffusion of the test investigations as an editorial boom of a specialized discourse.
\end{abstract}

Keywords: standards of proof, editorial boom, evidence discourse

\title{
I. Introducción
}

La palabra "estándar" es ajena al español. Proviene del inglés (standard) y se define como un adjetivo que se predica de algo que sirve como tipo, modelo, norma, patrón o referencia. También se usa como nombre masculino para referirse a un tipo, modelo, patrón, nivel. Como acción transitiva, "estandarización" significa tipificar, es decir, ajustar varias cosas semejantes a un tipo o norma común. Estos significados de la Real Academia de la Lengua Española nos permiten entender que la palabra "estándar" se refiere a una serie de conceptos que - si se es optimista- deberían ser cuidadosamente delimitados para usarlos en contextos jurídicos y probatorios.

Rodrigo Coloma es uno de esos optimistas que buscan elucidar qué significa "estándar" en el proceso de valoración de la prueba. Pero Coloma no es un ingenuo. Adhiere a un optimismo epistémico desconfiado. Coloma sabe que la palabra "estándar" y que la locución "estándar de prueba" son ejemplos de usos opacos del lenguaje, para hablar de un modo oblicuo de la racionalidad que muchos esperan se instancie en el razonamiento judicial. Coloma desconfía porque, por un lado, tiene poca seguridad sobre las herramientas que utiliza para enfrentar el problema y; por otro, porque tiene pocas esperanzas de arribar a la disolución o la resolución de los problemas implicados en la valoración de la prueba. 
Los estándares de prueba y el boom editorial del discurso...

Es difícil criticar a un optimista desconfiado como Coloma. La razón es sencilla: no hay una tesis fuerte que cuestionar y es fácil compartir la desconfianza por las mismas razones o por otras análogas. Si se quiere compartir el punto de vista interno de quienes cultivan el derecho probatorio, las críticas podrían entonces apuntar a cuestiones de método o a la falta de tratamiento de algunos ejemplos que podrían estimarse como centrales en el proceso de adjudicación. No usaré estas estrategias. En lo que sigue, asumo un punto de vista externo a las controversias entre expertos en derecho probatorio. Voy a cuestionar la idoneidad de las metáforas al entender el uso de los estándares de prueba usando las figuras de umbral y prototipo, para intentar ilustrar el "vacío conceptual" sobre el que se construye el discurso referido a los estándares de prueba. Luego, voy a presentar reflexiones sobre por qué este discurso ha tenido tanta difusión en los últimos años. Aquí uso la palabra boom en sentido literario y editorial, como éxito o auge repentino de un tema o asunto.

\section{Dos metáforas desafortunadas}

La palabra "umbral" aplicada al uso de los estándares de prueba es una metáfora doble. Un umbral es la parte inferior de una puerta que opone en paralelo al dintel y, entonces, cuando se atraviesa el umbral se ingresa a un lugar. La palabra umbral también es un valor mínimo de una magnitud a partir del cual se produce un efecto determinado. La primera metáfora es espacial, la segunda es escalar. Ambas metáforas comparten la idea de que un umbral es un límite.

Entender el uso de los estándares de prueba como umbrales obedece a un espíritu cientificista que supedita la racionalidad a la posibilidad de hacer medible las magnitudes que gobiernan el mundo. Este espíritu fue

1 La expresión "vacío conceptual" quiere significar que los teóricos de la prueba no tienen un punto de partida incuestionable (un punto fijo), es decir, una red de conceptos teóricos bien elaborados (i.e. que se apoyen mutuamente) que logre hacer mensurables las variables probatorias. Ahora bien, este vacío no implica que sea imposible arribar a ciertos consensos o convenciones sobre aquello que se estudia. 
muy bien expresado por Galileo al referirse al trabajo científico: "medir todo lo mensurable y hacer mensurable todo lo medible". La metáfora del umbral supone, entonces, que contamos con algo que es una magnitud y no solo una cualidad o propiedad, así la metáfora supone que lo estudiado es (o puede ser) mensurable (podemos lograr medirlo) y podemos fijar un valor a partir del cual se produce un efecto ${ }^{2}$. Así, la metáfora del umbral explica el uso de los estándares de prueba como aquel valor mínimo a partir del cual se da por probado el hecho X en el contexto de un proceso judicial.

La metáfora del umbral es desafortunada, porque en lugar de resolver o disolver el problema lo convierte en un problema mal planteado. La teoría sobre la prueba de los hechos no ha logrado modelar una cualidad o variable (o conjunto de ellas) como una magnitud (o conjunto de ellas) que pueda(n) ser individualizada(s) y medida(s) del modo en que se supone posible tras la idea de umbral.

La palabra "prototipo" es una metáfora con un objeto. Hay dos significados de prototipo. En un primer significado, prototipo refiere a un ejemplar original o primer molde con el que se fabrica un objeto. En un segundo significado, es un ejemplar perfecto, patrón o modelo de una virtud, vicio, cualidad o aparato. Dejando de lado el primer significado, la metáfora que explica el uso de los estándares de prueba con el segundo significado de la palabra prototipo también obedece al espíritu cientificista porque evoca la noción de patrón de medida ${ }^{3}$. Tras

2 Según el Sistema Internacional de Unidades, existen siete magnitudes fundamentales, cada una con su patrón de medida. Ellas son: Longitud, Masa, Tiempo, Intensidad eléctrica, Temperatura, Intensidad luminosa y Cantidad de sustancia.

3 Un patrón de medida (internacional) es un hecho aislado y conocido que sirve como fundamento para crear una unidad de medir magnitudes. Así, por ejemplo, un patrón para medir el tiempo es el segundo que se define como: "Un segundo es la duración de 9192631770 oscilaciones de la radiación emitida en la transición entre los dos niveles hiperfinos del estado fundamental del isótopo 133 del átomo de cesio (133Cs), a una temperatura de 0 K”. Entrada 'Segundo' del diccionario de Lógica y Filosofía de la Ciencia de Jesús Mosterín y Roberto Torretti. Alianza Editorial, segunda edición. 2010, Madrid, España.

El patrón para medir la temperatura es el grado kelvin. Este se define: un grado kelvin es igual a la 1/273,16 parte de la temperatura termodinámica del punto triple del agua (el punto triple del agua tiene una temperatura de cero grados centígrados, 273,16 grados 
Los estándares de prueba y el boom editorial del discurso...

la metáfora del prototipo está, nuevamente, la idea de mensurabilidad de una magnitud que influye en la valoración de la prueba, porque un patrón es un objeto que permite construir escalas de medición e instrumentos para medir cierta magnitud.

Pienso que no merece la pena continuar reformulando el problema de los estándares de prueba con estas metáforas y usando este lenguaje que se ha tomado prestado de la filosofía de la ciencia. Quizá, es mejor reconocer la carencia de conceptos que permitan describir, explicar, modelar y/o reconstruir el proceso de toma de decisiones en cuya virtud, a partir de cierto(s) paso(s) o movimiento(s), se acepta como probado un hecho $\mathrm{X}$ con base en un conjunto de medios de prueba C. En lo que sigue mostraré lo inadecuado de las metáforas usando un ejemplo de la física (jotra metáfora!) para hacer más observables las diferencias entre el discurso científico y el discurso de los juristas. Luego, analizaré el modo en que se ha estructurado el discurso probatorio en los últimos años y qué papel cabe al trabajo de Rodrigo Coloma en ese discurso.

\section{Las sensaciones térmicas, el calor y la temperatura ${ }^{4}$}

Medir la temperatura exige distinguir esta noción de otra que le es semejante a nivel sensoperceptible: el calor. En la antigüedad, el calor (calórico) era concebido como una sustancia sui generis, fluida, indes-

kelvin y el patrón de medidas de la masa es: un kilogramo es igual a la masa del prototipo de Platino-Iridio conservado en el Laboratorio Internacional de Pesas y Medidas. Entrada 'Kelvin' del diccionario de Lógica y Filosofía de la Ciencia de Jesús Mosterín y Roberto Torretti. Alianza Editorial, segunda edición, 2010, Madrid, España.

Un patrón para medir la masa es el kilogramo que "es igual a la masa del prototipo de Platino-Iridio conservado en el Laboratorio Internacional de Pesas y Medidas”. Entrada 'Kilogramo' del diccionario de Lógica y Filosofía de la Ciencia de Jesús Mosterín y Roberto Torretti. Alianza Editorial, segunda edición. 2010, Madrid, España.

4 En toda esta sección sigo muy de cerca las entradas 'Calor', 'Calórico' y 'Temperatura' del diccionario de Lógica y Filosofía de la Ciencia de Jesús Mosterín y Roberto Torretti. Alianza Editorial, segunda edición, 2010, Madrid, España. 
tructible. Solo en 1850 los resultados de Joule hicieron comprensible el calor como energía térmica.

El calor es diferente de la sensación térmica. Percibimos que algo entra a nuestro cuerpo a través de la piel cuando tenemos una sensación cálida y que sale de nuestro cuerpo cuando sentimos frío. Se llama "sensación térmica" y es una reacción de nuestro cuerpo al tocar o percibir por nuestra piel un objeto caliente o frío. La sensación térmica depende de dos 'estados térmicos': del estado de calor o frío de nuestro cuerpo y del estado de calor o frío del objeto. Por ejemplo, si pongo la mano derecha sobre una fogata $\mathrm{y}$, al mismo tiempo, con la mano izquierda sostengo cubos de hielo y enseguida introduzco ambas manos en un cubo de agua potable, sentiré tibieza en la mano derecha y frío en la mano izquierda.

Las sensaciones térmicas son útiles para establecer una jerarquía tosca de estados térmicos. Esta jerarquía se funda en las siguientes ideas: a) Las sensaciones térmicas nos permiten afirmar que la temperatura entre dos objetos puede ser igual, mayor o menor, b) La igualdad de temperaturas es una relación de equivalencia, c) Las relaciones mayor y menor son relaciones transitivas, d) Cuando dos objetos de diferente temperatura son puestos en contacto, al cabo de un tiempo, sus temperaturas se igualan y, e) Existen cambios en los objetos que son independientes de las sensaciones térmicas ( $v . g r$. la dilatación de los metales).

Antes de 1715 no existía una noción fina de 'temperatura' como la que tenemos hoy. La razón es sencilla: los termómetros no eran comparables entre sí. Fue Fahrenheit quien consiguió calibrar dos instrumentos con una escala común. Antes de este momento, la escala era relativa al termómetro usado para definirla. Solo en 1741 Celsius construyó su escala de medición de la temperatura basándose en el volumen de una columna de mercurio a nivel del mar. Se fija como cero grados la medición de un recipiente con agua en vías de congelarse. Se estipula que la temperatura aumenta en un grado cada vez que

5 Hoy los termómetros se calibran con una escala termodinámica basada en el trabajo de Lord Kelvin. 
Los estándares de prueba y el boom editorial del discurso...

el volumen de la columna de mercurio crece en 0,01 V. Así, el punto de ebullición del agua queda fijado en cien grados.

Esta breve crónica sobre la construcción del concepto de 'temperatura' ilustra varias diferencias entre el estado actual del discurso científico y el discurso sobre la prueba de los hechos ${ }^{6}$. Los juristas, siguiendo a los filósofos de la ciencia, han postulado el 'grado de creencia' u otras nociones semejantes como 'grado de aceptación'7 o 'fuerza probatoria' u otras semejantes, tal y como si fuesen magnitudes que intervienen en el proceso de toma de decisiones del juez. El discurso de algunos teóricos de la prueba y juristas supone que, de algún modo, estas nociones son mensurables. A mi juicio, he ahí el principal problema del discurso probatorio en boga. Este modo de reconstruir el trabajo de los jueces supone una suerte de "termómetro probatorio" y por ello aspira a contar (y a usar) estándares de prueba para construir un modelo conceptual que haga comparables los resultados obtenidos de diferentes casos tal y como si se tratara de medir su temperatura, es decir, midiendo una variable (o un conjunto de variables) en diversos casos para compararlos, jerarquizarlos y tratar de modo semejante a quienes resultasen con mediciones equivalentes.

La observabilidad de una magnitud es un resultado, no un punto de inicio ni un dato autoevidente o incuestionable. Lo mismo ocurre con la mensurabilidad de una magnitud. Ambas acciones (observar y medir) son procesos prácticos que dependen de la teoría. Ello es así porque para medir una variable es necesario resolver no menos de cuatro tipos de problemas: a) problemas cognitivos: medir una variable genera una forma de pensar que hace cognoscible una porción de la realidad y hay capacidades intelectuales que solo se pueden ejercitarse a través de la actividad de medir. Entonces, entre la actividad y la teoría hay una

6 Chang, H., Inventing temperature. Measurement and scientific progress, Londres, Oxford University Press, 2004.

7 "Glaubensgrad, degré de croyance, degree of belief. En una interpretación personalista de la probabilidad, grado de creencia de la persona $X$ en el enunciado $\mathrm{p}$ a la probabilidad de $\mathrm{X}$ atribuye a $\mathrm{p}$. El grado de creencia de $\mathrm{X}$ en $\mathrm{p}$ se mide por la fracción de 1 que $\mathrm{X}$ está dispuesto a pagar a cambio de la seguridad de recibir 1 sí y solo sí p es verdadero". Entrada 'grado de creencia' del diccionario de Lógica y Filosofía de la Ciencia de Jesús Mosterín y Roberto Torretti. Alianza Editorial, segunda edición, 2010, Madrid, España. 
retroalimentación ${ }^{8}$; b) problemas tecnológicos: es necesario resolver cómo se construirán los instrumentos de medición; c) problemas metodológicos: es necesario disponer de reglas (técnicas regulativas y constitutivas) para realizar la medición y operar los instrumentos de medición y d) problemas de justificación: es necesario formular criterios para justificar el modo de construir y operar los instrumentos y para interpretar las lecturas de los datos obtenidos, entre otras decisiones.

Estos cuatro tipos de problemas no se discuten en el discurso probatorio que asume la metáfora del estándar de prueba como umbral. El discurso de los juristas parece olvidar que en materias de prueba judicial (todavía) no hay nociones que sean equivalentes a magnitudes. Los juristas no han conceptualizado lo suficiente la(s) magnitud(es) a estudiar (ni sus relaciones) y, entonces, desde un punto de vista externo, es poco sensato asumir que es posible tratarlas lingüísticamente como si fuesen mensurables mediante la construcción de nociones como la de estándar de prueba. Si no hay una magnitud claramente definida que mensurar se trabaja sobre una red conceptual inexistente o muy frágil ${ }^{9}$.

La fragilidad conceptual a la que hago referencia hace que sea muy interesante analizar la progresiva difusión del discurso de quienes participan en la investigación de los problemas de prueba. Hay que recordar que toda ciencia normal es dogmática en relación al paradigma que la sustenta y, entonces, solo la filosofía y la sociología pueden analizar el proceso de construcción de consensos y la paulatina aceptación del discurso científico como conocimiento nuevo. La cuestión no es solo analizar la coherencia argumental de quienes participan en el discurso

8 Es posible sostener que los instrumentos de medición operan como una extensión de la mente humana. Meli, D. B., Thinking with Objects: The Transformation of Mechanics in the Seventeenth Century, Baltimore: The Johns Hopkins University Press, 2006.

9 Dei Vecchi señala al respecto: "La cuestión ocuparía un lugar central en la agenda epistemológico-jurídica de los años sucesivos a Discusiones 3. Sin embargo, la epistemología empezaría a mostrar sus limitaciones. En particular, su relativa falta de idoneidad para ofrecer unidades de medida de la prueba, y su consecuente impotencia para determinar criterios de suficiencia concluyentes". Dei Vecchi, D., "Tres discusiones acerca de la relación entre prueba y verdad", Discusiones 13, 2, 2013, p. 233-264. 
Los estándares de prueba y el boom editorial del discurso...

probatorio, sino también determinar si esa coherencia es un paradigma o solo una confluencia de intereses individuales ${ }^{10}$.

\section{El discurso sobre el derecho probatorio}

El ejemplo (la metáfora) expuesto en la sección anterior muestra que usar (de modo directo o indirecto) las nociones que estudian el trabajo científico para investigar el trabajo de los jueces produce distorsiones. ¿Por qué ha tenido éxito un discurso que puede distorsionar aquello que estudia? Desde el punto de vista externo a quienes cultivan el derecho probatorio, parece poco razonable el intento de construir un concepto de estándares de prueba sobre el vacío. La fortuna de discursos científicos sobre conceptos vacíos ha sido profusamente investigada en la filosofía de la ciencia con el auxilio de herramientas históricas. Los trabajos sobre el 'calórico', el 'flogisto' y el 'éter' son ejemplos clásicos $^{11}$. No puedo abordar una tarea semejante en estas líneas. Solo aventuro una conjetura.

El éxito de la analogía (parcial e indirecta) entre el juez y el científico mediante el uso de terminología como 'estándares', 'umbrales', 'prototipos', 'hipótesis probatoria' o 'hechos indiciarios' puede explicarse por su utilidad para quienes participan del discurso: los investigadores. Echar mano al diccionario de la filosofía de la ciencia, por un lado, es económico, porque ahorra el trabajo de construir un léxico para la prueba de los hechos en el derecho diferenciado de la dogmática tradicional y de la filosofía del derecho tradicional y; por otro, resulta muy provechoso, porque permite una rápida asociación entre

10 Bloor, D., Knowledge and social imaginery, Londres: Routledge and Kegan, Paul, 1976. Bloor, D., "The strenghs of the strong programme", Philosophy of the social sciences, II, 2, 1981, pp. 199-213.

11 Todos estos ejemplos se pueden revisar en el Diccionario de Lógica y Filosofía de la Ciencia de Jesús Mosterín y Roberto Torretti. Alianza Editorial, segunda edición. 2010, Madrid, España. Para una crítica histórico-filosófica a la sustitución que hace Lavoisier del flogisto por el calórico ver Chang, H., Inventing Temperature. Measurement and Scientific Progress, Londres: Oxford University Press, 2004. 
el discurso probatorio y la tradición de la filosofía de la ciencia. Se genera así un efecto social positivo: la distinción entre quienes investigan 'prueba', y quienes hacen 'dogmática' o 'teoría del derecho'12.

Sobre la base de esta conjetura creo que hay no menos de cinco razones que explican por qué algunos juristas y teóricos del derecho han comenzado a participar en el discurso probatorio y por qué se ha generado un boom editorial.

a) Las fuentes sobre la prueba son extravagantes. Las disposiciones normativas que el legislador formula al regular la prueba en contextos judiciales son peculiares. Listaré algunas de estas características: (a) las disposiciones son fragmentarias y su ubicación en la legislación es poco sistemática, (b) los textos normativos usan locuciones y expresiones que carecen de una sólida tradición en la cultura jurídica del civil law, (c) muchas de las disposiciones pueden considerarse cláusulas generales de disposición, norma explícita y norma implícita en terminología de Chiassoni ${ }^{13}$ y (d) el modo en que son escritas las disposiciones no permite ejercitar de forma más o menos automática una interpretación correctora con códigos hermenéuticos similares a los usados para crear, prevenir o resolver lagunas y antinomias en otros sectores del ordenamiento jurídico. Entonces, parece que las normas que resultan de la actividad interpretativa no dialogan fácilmente con las normas sustantivas.

b) El discurso de las fuentes sobre la prueba posee un lenguaje peculiar. Las expresiones sobre la prueba de los hechos que usa el legislador son opacas. Es un lenguaje en donde abundan conceptos jurídicos indeterminados, cláusulas generales, remisiones y reenvíos entre otras figuras. Además, combina un léxico informal con uno técnico. Expresiones como 'valoración', 'sana crítica', 'hecho', 'relevancia', 'máximas de la experiencia', 'principios de la lógica', 'hechos sustanciales, pertinentes y controvertidos', 'racionalidad', 'verdad material', 'prudente criterio', 'razonable', etcétera son usadas por el legislador, la dogmática, la jurisprudencia y la teoría del derecho de forma relativamente opaca. AdeRevista de Derecho Privado, Universidad del externado de Colombia, 21, 2011, p. 89-106. 
Los estándares de prueba y el boom editorial del discurso...

más, existen muy pocas convenciones lingüísticas sobre su definición y, las que existen, tienen un campo de aplicación muy reducido o son incapaces de reducir la ambigüedad de las palabras o de redefinir los conceptos reduciendo su vaguedad.

Creo que esta terminología dota a los discursos sobre la prueba de un halo de reflexión perspicua y de progreso científico. Un progreso que es capaz (o al menos eso intenta) de construir un continuum entre la toma de decisiones en situaciones cotidianas por personas comunes y corrientes y el modo en que los jueces operan (o debiesen hacerlo).

c) La racionalización del trabajo judicial es una ideología en boga. En el discurso de los juristas circula una tesis de política del derecho (probatorio) que defiende las bondades de la racionalidad en la decisión de los hechos. Esta ideología sustenta, a mi juicio, expectativas jurídicas y científicas un tanto desmesuradas. El legislador, los jueces, los juristas y alguna proporción de los teóricos del derecho pretenden controlar el arbitrio judicial usando el discurso probatorio. En este sentido, por ejemplo, la noción de estándar de prueba connota la posibilidad de estandarización del trabajo judicial y, en alguna medida, con ello se cifran esperanzas en la universalización de los juicios probatorios ${ }^{14}$. Las expectativas científicas también son altas. Ejemplo de esto es el uso de las expresiones 'epistemología jurídica' y 'epistemología judicial' en libros, artículos y seminarios sobre derecho probatorio ${ }^{15}$. Tras el uso de estas locuciones sospecho no menos de dos funciones ideológicas: por un lado, la distanciación lingüística de la dogmática, para lograr distinción y reconocimiento ${ }^{16}, \mathrm{y}$, por otro, algún grado de confianza en la construcción de un discurso que evite la fragmentación del mundo y

${ }^{14}$ Las expectativas sobre el control de errores judiciales parecen engarzarse con estas ideas. Un ejemplo de ello es Malem, quien señala: "Además, en la apreciación de la prueba se producen errores cuando se aplican estándares de prueba inadecuados. Los estándares de prueba son los criterios o pautas que se utilizan para determinar si una hipótesis probatoria ha recibido o no suficiente apoyo como para ser corroborada". Malem, J., Error judicial y formación de jueces, Barcelona: Gedisa, 2008.

${ }^{15}$ Es probable que este uso editorial de las locuciones en cuestión se deba al título que Marcial Pons dio al libro de Larry Laudan Verdad, error y proceso penal: un ensayo sobre epistemología jurídica, que fue publicado en 2013.

${ }^{16}$ Sobre las nociones de distinción y reconocimiento ver Bourdieu, P., ídem. 
que explique y/o justifique de forma integradora muchas actividades diferentes sobre la prueba de hechos.

d) El discurso académico se presenta como una tecnología para los operadores. Vinculada a la idea anterior hay una ideología tecnocrática en el discurso jurídico sobre la prueba. Progresivamente, se ha instalado una idea sobre la especialización que reclaman las investigaciones sobre "el-problema-de-la-prueba". Los artículos sobre la prueba son cada vez más técnicos (y más oscuros para el lego o semilego que cultiva otras disciplinas) y esta forma de tratar el problema les reviste de un halo de cientificidad que sostiene la confianza del lector.

e) La supuesta utilidad de las investigaciones. El discurso de muchos dogmáticos y teóricos del derecho se ha presentado como un aporte a la solución del "problema-de-la-prueba". Creo que esta estrategia permite que el discurso tenga un impacto editorial más extenso (y, entonces, el producto editorial resulta más masivo). La masividad es fácilmente explicable: la nociones como "hecho probado", "estándar de prueba" y otras semejantes son muy dúctiles ya que no se vinculan directamente a las fuentes del derecho permitiendo a los litigantes, a los jueces y a los juristas de diferentes países construir interpretaciones correctoras de sus disposiciones y elaborar discursos para justificar y excusar sus decisiones.

f) Los editores comprendieron que el discurso probatorio es transnacional. Todos los rasgos listados dotan a los autores del boom de una importante cualidad editorial: el discurso probatorio no es local, sino que se desatienden las fuentes del derecho que limitan el alcance de los trabajos típicamente jurídicos. Así, los textos del boom plantean los problemas probatorios con un nivel de abstracción y generalidad que les permite ser leídos en muchos ordenamientos jurídicos diversos. 
Los estándares de prueba y el boom editorial del discurso...

\section{El boom del discurso probatorio}

La palabra inglesa 'boom' se usa en el marketing para referirse a una brusca alza en las ventas de un producto. En literatura ha sido usada, por ejemplo, para etiquetar el incremento en la literatura latinoamericana entre la década de los sesenta y hasta principios de los ochenta. Aquí uso la palabra boom en este sentido puramente literario y editorial. Entiendo por boom un fenómeno de aumento de la difusión, el reconocimiento y la influencia de quienes investigan sobre la prueba ${ }^{17}$.

Aunque hace falta una investigación profunda para asegurarlo, creo que es posible sostener que desde el año 1999, de forma creciente, las investigaciones sobre la prueba se han incrementado ${ }^{18}$. Creció su volumen de producción, su ámbito de circulación y su tasa de consumo por parte de los dogmáticos, de los abogados y de los jueces. Aunque es difícil de delinear, creo que hay tres conjuntos que son clave para delimitar quiénes han sido parte de este movimiento: un cierto grupo de escritores, investigadores o autores; un conjunto de textos, artículos, revistas y libros principalmente; y un conjunto de ideas sobre cómo es y cómo debería ser la prueba judicial ${ }^{19}$ y su investigación. En las próximas páginas intentaré justificar con datos la existencia del referido boom.

\section{V.1. La invención del "derecho probatorio" en el catálogo librero español}

Clasificar los libros según la materia que tratan no es un asunto puramente científico o de interés para la gestión bibliotecaria. Se trata de un

${ }^{17}$ Es importante dejar en claro que la expresión boom no dice nada sobre el contenido de las publicaciones, es decir, no implica una evaluación de su importancia, novedad, utilidad, impacto académico o científico. En este sentido, se trata de una categoría que atiende solo al fenómeno editorial: la divulgación de un discurso.

${ }^{18}$ Es verdad que hay textos importantes que fueron publicados con anterioridad. Un ejemplo se encuentra en un antiguo artículo de Perfecto Andrés. Ver: Perfecto Ibañez, A, "Acerca de la motivación de los hechos en la sentencia penal", Doxa, 12, 1992, pp. 257-299. Es claro que un análisis bibliométrico detallado debería considerar este tipo de textos, pero ese no es el propósito de este artículo.

${ }^{19}$ Vale la pena señalar que un conjunto de ideas no es un ideario. 
problema comercial. Según explica el sitio de DILVE (Distribuidor de información del libro español en venta) ${ }^{20}$, el catálogo IBIC (International Book Industry Categories) es un sistema de calificación internacional de libros por materias con una orientación comercial. El sistema es análogo a BIC (Book Industry Communication) usado en Reino Unido, Australia y Nueva Zelanda y a BISAC (Book Industry Study Group) de uso en Estados Unidos y Canadá. Señala el sitio de DILVE:

E1 sistema IBIC se basa en unos 2.600 códigos de materias, agrupados jerárquicamente en 18 categorías (Artes, Lengua, Literatura y estudios literarios, Ficción y temas afines, Derecho, Medicina...). Del mismo modo, propone 900 códigos denominados 'calificadores' para indicar, si se desea, la localización geográfica, las lenguas de la obra, los períodos históricos, los fines didácticos y la edad de interés $[\ldots]^{21}$.

En España, el comité de gestión del IBIC está integrado por varios agentes de la industria del libro. En el área jurídica, las editoriales Wolters Kluwer y Marcial Pons tienen la tarea de revisar la clasificación ${ }^{22}$.

La configuración comercial del IBIC permite entender por qué al consultar la base de datos de los libros editados en España se presentan

${ }^{20} \mathrm{https}$ ///www.dilve.es/dilve/dilveweb/dilve_IBIC.jsp

${ }^{21}$ Continúa el sitio web de DILVE: "En 1998 se hizo pública la primera versión del estándar, en cuya elaboración participaron representantes destacados del sector. La última versión (v 2.1), que ha sido la referencia para su adaptación a España, se hizo pública en diciembre del 2010. En octubre de 2011, la clasificación BIC pasa a denominarse IBIC para recoger las adaptaciones del sistema a diferentes mercados como los de Italia, España, Alemania, Noruega, Suecia, Portugal, etc.”.

"En España, la elección del sistema de clasificación de materias IBIC para el mercado del libro ha sido fruto de un acuerdo entre representantes de todo el sector comercial (editoriales, distribuidoras, librerías y Agencia del ISBN), coordinados por la Federación de Gremios de Editores de España por medio de DILVE" (https://www.dilve.es/dilve/dilveweb/dilve_IBIC.jsp)

${ }^{22}$ Según informa el sitio DILVE, "En estos momentos se está llevando a cabo un análisis más detallado del ámbito jurídico y del científico-técnico, con la colaboración de algunas de las editoriales y librerías más significativas así como en coordinación con el Comité Internacional IBIC" (https://www.dilve.es/dilve/dilveweb/dilve_IBIC.jsp) 
Los estándares de prueba y el boom editorial del discurso...

ciertas paradojas $^{23}$. En el periodo entre 1990 y 2000 el resultado de la búsqueda de los libros cuya materia es derecho ${ }^{24}$ y que usan la palabra "prueba" en el título ${ }^{25}$ tiene como resultado solo dos títulos. Uno de ellos es el libro Los hechos en el derecho: bases argumentales de la prueba de Marina Gascón Abellán. Este libro fue publicado en 1999 en la colección Monografias jurídicas de la editorial Marcial Pons ${ }^{26}$.

Cuando, usando los mismos criterios, la búsqueda incluye el periodo entre 2000 y 2010 el número de libros publicados crece a ocho ${ }^{27}$. Y cuando se busca entre 2011 y 2017 (usando los mismos dos parámetros) no hay títulos publicados. Si, en cambio, la materia "derecho" se reemplaza por "procedimiento civil: derecho probatorio", surgen ocho títulos publicados en el periodo ${ }^{28}$ y si se elimina el requisito de la palabra

23 La base de datos está disponible en el sitio web: https://www.mecd.gob.es/culturamecd/areas-cultura/libro/bases-de-datos-del-isbn/base-de-datos-de-libros.html

24 En el buscador he fijado como índice la materia derecho sin ninguna adjetivación adicional.

25 Manual práctico de la prueba pericial médica cuyos autores son Martínez María Francisca y García-Blázquez Manuel de la editorial Comares y La prueba y medios de prueba, de Roma al derecho moderno cuyos autores son Camacho Fermín, Bello, Silvestre y Domínguez Paula de la editorial Servicio de Publicaciones de la Universidad Rey Juan Carlos. Con otros criterios de búsqueda es posible encontrar obras como, por ejemplo, La prueba en el procedimiento de gestión tributaria de Ana Pita publicado en 1998 por Marcial Pons.

26 La primera edición de este texto figura clasificado en dos materias: derecho comparado y proceso civil, en cambio, la segunda y la tercera ediciones fueron clasificadas solo como derecho comparado.

27 Esos libros, ordenados por título y excluidos los impertinentes para la investigación jurídica incluyen: La carga de la prueba en la jurisprudencia romana clásica: (exégesis de 22.3) de José Miguel Piquer editado por Edisofer (2006), Disposiciones generales sobre la prueba de Francisco López Simó de editorial La ley (2001), Empresa y prueba informática (sin autor) de Bosch (2006), Manual práctico de la prueba pericial médica de María Francisca Martínez y Manuel García-Blázquez de editorial Comares (2000), La prueba pericial en el proceso civil de Pilar Ledesma editado por el Consejo General del Poder Judicial (2006), La prueba y los medios de prueba, de Roma al derecho moderno de Fermín Camacho, Silvestre Bello y Paula Domínguez editado por el Servicio de Publicaciones de la Universidad del Rey Juan Carlos (2000), La prueba de Michele Taruffo de Marcial Pons (2008) y, Valoración del daño corporal: legislación, metodología y prueba pericial médica de César Borobia de la editorial Elsevier Mansson (2007).

28 El listado incluye los siguientes títulos. Análisis de la prueba de Terence Anderson, David Schum y William Twining editado por Marcial Pons (2016); La prueba de reconocimiento judicial, sin autor, editado por Bosh (2012); La prueba pericial contable en 
"prueba" en el título y se mantiene la materia "procedimiento civil: derecho probatorio" el resultado es treinta títulos publicados en el periodo. No deja de ser curioso que, la misma búsqueda en el periodo 1990 a 2000 da como resultado cero y en el periodo 2000 a 2010 el resultado es solo cuatro libros.

Los resultados de las búsquedas nos permiten lanzar una hipótesis: la clasificación IBIC "procedimiento civil: derecho probatorio" surgió en algún momento posterior al año 1999 con el objetivo de catalogar mejor las obras de derecho de prueba con fines comerciales, porque IBIC tiene esos fines. Ahora bien, los editores no saben muy bien qué cosas deben poner bajo esa etiqueta.

Algunos datos adicionales para sustentar esta apuesta. La traducción del libro Verdad, error y proceso penal: un ensayo sobre epistemología jurídica de Larry Laudan es clasificado como Filosofía del Derecho al igual que el libro Debatiendo con Taruffo ${ }^{29}$. Asismismo, La motivación de la sentencia civil ${ }^{30}$ es categorizado como derecho civil, derecho procesal y filosofía del derecho y La prueba de los hechos ${ }^{31}$ es clasificado como derecho procesal, filosofía del derecho y procedimiento civil: derecho probatorio. En cambio, La valoración racional de la prueba de Jordi Ferrer (2013) es clasificado por Marcial Pons en Filosofía: epistemología y teoría del conocimiento y Filosofía: lógica. Finalmente, una editorial pequeña como Bubok Publishing, en el año 2013, clasifica como Criminología el libro Decidir sobre los hechos: un estudio sobre la valoración racional de la prueba judicial de Evanilda Godoi.

las jurisdicciones civil, penal, contencioso-administrativa y laboral, de José Carlos Balagué (2012); Recomendación técnica 4 refor-CGE: la prueba pericial contable y económica en el proceso judicial español, sin autor, editado por el Consejo General de Economistas (2013); La valoración de la prueba de interrogatorio de Cristian Contreras editado por Marcial Pons (2015); La valoración de la prueba en el proceso civil de Xavier Abel, de editorial La Ley (2014) (en dos formatos, archivo de internet y en papel).

29 Libro colectivo publicado el año 2016 por Marcial Pons.

30 Esta es la clasificación de la primera edición del año 2011.

31 Esta es la clasificación de la primera edición del año 2002. 
Los estándares de prueba y el boom editorial del discurso...

\section{V.2. Los autores del boom}

Hacer un listado exhaustivo de autores que participaron del boom desde principios de la primera década de este siglo hasta hoy, es una tarea que no puedo abordar aquí. Una mirada rápida a los textos publicados permite aventurar que la lista podría extenderse, quizá, hasta dos docenas de nombres distribuidos por Ítalo-Iberoamérica. Se trata, entonces, de un número reducido de participantes.

Todo boom tiene un canon ${ }^{32}$. En las líneas que siguen no es posible (ni deseable) fijar la lista de autores canónicos del boom. Simplemente, hago un listado de autores sin pretensiones de exhaustividad.

En España el conjunto de autores que inicia el boom son tres figuras: Marina Gascón, Jordi Ferrer y Daniel González. De modo estipulativo, podemos fijar el inicio del boom en el año 1999. En ese año Marina Gascón publicó Los Hechos en el Derecho ${ }^{33}$, creo que por ese libro ella merece el título de pionera del discurso de prueba en habla hispana ${ }^{34}$. Luego de este primer paso, son los trabajos de Jordi Ferrer los que consolidan y aumentan el impacto del discurso probatorio y lo transforman en un boom. Además, es Ferrer quien convierte a Taruffo en una figura editorial en lengua castellana. Las investigaciones de Daniel González, aunque son centrales en el discurso probatorio que se analiza, están más atrás en cuanto a su impacto editorial ${ }^{35}$.

Los tres autores defienden (y discuten) dentro de un conjunto compartido de ideas: el racionalismo en materia de prueba. Este rasgo no

32 Aquí uso la palabra 'canon' en el sentido en que la usan los teóricos de la literatura. Bloom, H., El canon occidental, Barcelona: Anagrama, 1995.

${ }^{33}$ Gascón Abellán, M., Los hechos en el derecho. Bases argumentales de la prueba, Barcelona: Marcial Pons, 2004. En forma previa, se había publicado otro libro que influye indirectamente en el boom, ya que pese a tener su foco en cuestiones normativas, pone mucho énfasis en la determinación de los hechos. Me refiero a Ferrajoli, L., Derecho y razón. Teoría del garantismo penal, primera edición, Valladolid: Editorial Trotta, 1995. El texto en italiano es de 1989.

${ }^{34}$ El trabajo de Ferrer en relación a constituir a Taruffo en un referente para el mercado hispano parlante merece una investigación particular.

${ }^{35}$ La expresión 'impacto editorial' no tiene que ver con el contenido de los textos, sino con su capacidad para llegar al público. 
los convierte en un grupo, es solo uno de otros varios rasgos comunes. Algunas de esas otras propiedades compartidas que vale la pena considerar son las siguientes: a) cada uno de ellos ha publicado textos para discutir ideas provenientes del common law, b) los tres comparten (aproximadamente) los canales de comunicación, es decir, las editoriales y las revistas. En España funcionan la editorial Trotta, Marcial Pons y, en menor medida, la Fundación Coloquio Jurídico Europeo. En Italia, Il Mulino y Giuffré cuando editaba Analisi e diritto son sus casas editoras. Los artículos también se publican en un listado muy acotado de revistas. Las principales son Discusiones, Doxa e Isonomía.

Para analizar la posibilidad de que estemos frente a un boom editorial el número de publicaciones anuales sobre prueba es un dato interesante de observar. Luego del libro de Gascón, en el año 2002 la editorial Trotta publicó la traducción de Jordi Ferrer del libro $L a$ prueba de los hechos de Michele Taruffo ${ }^{36}$. En el mismo año, Jordi Ferrer publicó Prueba y verdad en el derecho por la editorial Marcial Pons y al año siguiente, el tercer número de la revista Discusiones se dedicó al problema de la prueba de los hechos. El subtítulo de la revista es claro: Prueba, conocimiento y verdad ${ }^{37}$. La revista inicia con una presentación de Jordi Ferrer y Daniel González. En ella, cuatro investigadores debaten sobre un texto de Taruffo que es el artículo inicial ${ }^{38}$. Los tres artículos que siguen son de Marina Gascón Abellán ${ }^{39}$, Perfecto Andrés Ibáñez ${ }^{40}$

${ }^{36}$ El libro original de Taruffo fue publicado el año 1992 por la editorial Giuffré. La editorial Trotta, con meridiana claridad, fijó tres materias para la traducción de Taruffo: Derecho Procesal, Filosofía del Derecho y Procedimiento civil: derecho probatorio. En cambio, Marcial Pons clasificó la primera edición del libro de Gascón como derecho comparado y proceso civil. En tanto que la segunda edición (2004) y la tercera (2010) fueron catalogadas como derecho comparado.

${ }^{37}$ El impacto de esta revista ha sido amplio. Una reciente publicación de Juan Mocoroa da cuenta de la influencia de ese debate más de diez años después. Mocoroa, J., "Breves comentarios sobre prueba y verdad", Inciso, Revista de investigaciones en Derecho y Ciencias Politicas, 18 (1), 2016. Disponible en: http://revistas.ugca.edu.co/index.php/inciso/ article/view/469/903

${ }^{38}$ El trabajo en cuestión se titula Algunas consideraciones sobre la relación entre prueba y verdad.

${ }^{39}$ El artículo se titula "Concepciones de la prueba. Observación a propósito de Algunas consideraciones sobre la relación entre prueba y verdad, de Michele Taruffo".

${ }^{40}$ El artículo se titula "Sobre prueba y proceso penal". 
Los estándares de prueba y el boom editorial del discurso...

y Andrés Bouzat junto a Alejandro S. Cántaro ${ }^{41}$. La revista termina con un artículo en donde Taruffo replica a sus críticos ${ }^{42}$.

En el año 2004, Jordi Ferrer publica Prova e verità nel diritto en la editorial italiana Il Mulino. En el 2005 Trotta inicia las ventas de la segunda edición de La prueba de los hechos ${ }^{43}$ y Marcial Pons publica Carga de la prueba y sociedad del riesgo de Guillermo Ormazábal y la segunda edición del libro Prueba y verdad en el derecho de Jordi Ferrer ${ }^{44}$. Otras editoriales como Bosch también se suman a la publicación de textos sobre prueba ${ }^{45}$. En el año 2007 Marcial Pons publica el libro La valoración racional de la prueba de Jordi Ferrer ${ }^{46}$ y Tirant lo Blanch publica La prueba y el control de los hechos por la jurisdicción contencioso administrativa de David Blanquer. Creo que está bastante claro que, a ocho años del libro de Gascón, las palabras 'prueba' y 'hecho' son ya etiquetas que las editoriales usan para posicionar títulos en los anaqueles de las librerías.

En el año $2008^{47}$ Marcial Pons vuelve a editar a Michele Taruffo, esta vez en conjunto con Jordi Ferrer, se trata del libro titulado $\mathrm{La}$ prueb $^{48}$ y la editorial del Coloquio Jurídico Europeo no se queda atrás y publica Consideraciones sobre la prueba judicial de Michele Taruffo. E1 2009 es importante porque podría fijarse ahí el inicio del impacto del fenómeno editorial del discurso probatorio a este lado del Atlántico. Ese año, en Argentina la editorial Hammurabi publica Prueba y convicción judicial en el proceso penal de Perfecto Andrés Ibáñez. En Perú

41 Este trabajo se titula "Verdad y prueba en el proceso acusatorio".

42 Este trabajo se titula "Algunos comentarios sobre la valoración de la prueba".

43 Ese año la editorial peruana Palestra y la colombiana Temis publican Questio facti: ensayos sobre prueba, causalidad y acción de Daniel González Lagier.

44 La segunda edición de la traducción española fue clasificada en Proceso civil.

45 Ese año la mencionada editorial publica La prueba de los hechos en el proceso: aspectos de ley aplicable de Joaquim-Joan Forner i Delaygua.

46 La base de datos de libros editados en España consigna como autor a Jordi Ferrer. El sitio worldcat.org, en cambio, consigna como coautor a Larry Laudan. La materia de este libro es Filosofia: epistemología y teoría del conocimiento y Filosofia: lógica.

47 Ese año ingresa a la discusión Juan Carlos Bayón con un capítulo titulado "Epistemología, moral y prueba de los hechos: hacia un enfoque no benthamiano". El artículo está publicado en el libro Analisi e diritto del año 2008, pp. 15-34.

48 Son coautores Michele Taruffo y Jordi Ferrer. La materia del libro es Derecho. 
ARA publica Proceso, prueba y estándar de Marina Gascón y, en Chile, la editorial Metropolitana edita una compilación de trabajos de Michele Taruffo titulada La prueba: artículos y conferencias. En España, Trotta lanza la tercera edición de La prueba de los hechos.

En el año $2010^{49}$, el Instituto de Investigaciones Jurídica-UNAM publicó un libro colectivo bajo el título Estudios sobre la prueba cuyos autores principales son Jordi Ferrer, Marina Gascón y Daniel González Lagier. Ese mismo año, Marcial Pons publicó la traducción de otro libro de Michele Taruffo; Simplemente la verdad: el juez y la construcción de los hechos ${ }^{50}$ y el libro La valoración de la prueba de Jordi Nieva ${ }^{51}$. Además, se lanza la tercera edición del título Hechos en el derecho: bases argumentales de la prueba de Marina Gascón.

$\mathrm{Al}$ año siguiente, en 2011, Trotta editó La motivación de la sentencia civil, que es la traducción española del original italiano de Taruffo ${ }^{52}$. Marcial Pons edita La prueba: un análisis racional y práctico ${ }^{53}$ de Rodrigo Rivera y ese año Trotta comienza la venta de la cuarta edición de $L a$ prueba de los hechos ${ }^{54}$. En 2012 la editorial chilena Metropolitana volvió a publicar a Taruffo bajo el título Consideraciones sobre la prueba y motivación de la sentencia civil. En Colombia la Universidad del Externado publica Cuestiones probatorias de Marina Gascón. En Argentina ese año la editorial Hammurabi publicó a Larry Laudan con el título El estándar de prueba y las garantías en el proceso penal. Quizá aquí hay un giro en el boom. El foco de la discusión fue modificado por la traducción de Laudan al español. Esta es una hipótesis. Mi única fuente para hacer tal apuesta es

${ }^{49}$ En Chile, ese año se defiende la primera tesis en derecho probatorio del país. La obra del profesor Jorge Larroucau Torres se tituló La prueba en el proceso civil. El tribunal de la investigación estuvo integrado por Michele Taruffo. Información disponible en: http:// www.derecho.uchile.cl/postgrado/doctorado-en-derecho/53073/tesis-defendidas

${ }^{50}$ La editorial clasificó este libro como Derecho comparado.

${ }^{51}$ Este libro fue clasificado por la editorial como Proceso civil.

52 El original en italiano fue publicado el año 1975 por la editorial CEDAM.

${ }^{53}$ Este libro fue catalogado como Proceso civil.

${ }^{54}$ En México, Fontamara publicó el libro Estudios sobre la prueba. Obra colectiva que cuenta con la participación de Jordi Ferrer; Marina Gascón; Daniel González y Michele Taruffo entre otros. 
Los estándares de prueba y el boom editorial del discurso...

el balance que hizo Dei Vecchi en Discusiones XIII ${ }^{55}$. En la nota 61 de este trabajo, Dei Vecchi dejó constancia de un hecho muy elocuente: la expresión "estándar de prueba" solo figura en la página 93 de la revista Discusiones que dio uno de los primeros pasos del boom ${ }^{56}$.

En el año 2013 Marcial Pons publicó un libro colectivo coordinado por María del Carmen Vázquez bajo el título Estándares de prueba y prueba cientifica. Ensayos de epistemología jurídica ${ }^{57}$, un libro de Larry Laudan con el título Verdad, error y proceso penal: un ensayo de epistemología jurídica ${ }^{58}$ y un libro de Michele Taruffo y Jordi Nieva titulado Neurociencia y proceso judicial ${ }^{59}$. Ese mismo año, el Tribunal Electoral del Poder Judicial de la Federación de Estados Mexicanos publicó la serie cuadernos de divulgación con el título Verdad, prueba y motivación en la decisión sobre los hechos.

En el año 2015 la Universidad de Los Andes (Colombia) publicó un libro colectivo titulado Nuevas tendencias del derecho probatorio en donde participaron Michele Taruffo y Jordi Ferrer, entre otros autores. Marcial Pons lanzó al mercado el libro de Carmen Vázquez: De la prueba científica a la prueba pericial ${ }^{60}$ y el libro La valoración de la prueba de interrogatorio de Cristian Contreras y Jordi Nieva ${ }^{61}$. En América Latina, Andrés Páez publicó Hechos, evidencia y estándares de prueba. Ensayos de epistemología jurídica por la Universidad de los Andes. Desde Chile, Flavia Carbonell, Rodrigo Coloma y yo mismo coordinamos la traducción del libro Analysis of evidence de Terence Anderson, David Schum y William Twining, que lanzó Marcial Pons con el título Análisis de la

55 Dei Vecchi, D., "Tres discusiones acerca de la relación entre prueba y verdad", Discusiones, 13, 2, 2013, pp. 233-264.

56 Aunque no se puede desconocer que hay trabajos previos de Gascón, Ferrer y Bayón, entre otros, que tratan los problemas de los estándares de prueba, el punto no es ese. Se trata de determinar cuándo la locución "estándar de prueba" pasó a ser central en el boom editorial del discurso probatorio.

${ }^{57}$ La editorial clasificó este libro como Filosofía del Derecho.

${ }^{58}$ La editorial clasificó este libro como Filosofía del Derecho.

${ }^{59}$ La editorial clasificó este libro como Derecho Procesal.

${ }^{60}$ La editorial clasificó este libro como Filosofía del Derecho

${ }^{61}$ La editorial clasificó el libro como Derecho Procesal: derecho probatorio. 
prueba $^{62}$. En 2016 Marcial Pons publicó el libro colectivo Debatiendo con Taruffo ${ }^{63}$, bajo la coordinación de Carmen Vázquez y Jordi Ferrer.

A la fecha de la publicación de este texto también integra el boom la reciente traducción de Perfecto Andrés Ibáñez del libro de Giulio Ubertis Elementos de epistemología del proceso judicial, publicado por editorial Trotta ${ }^{64}$.

\section{VI. ¿Qué posición ocupa el trabajo de Rodrigo Coloma en el boom del discurso probatorio?}

Todo boom es solo una burbuja a punto de estallar. Los editores, esos "empresarios de la ideología" o "mercaderes de la cultura" siempre tienen dos caras, como Jano, una de ellas mira al comercio y otra al arte ${ }^{65}$. Entonces, si se acepta que hay un boom, parece sensato no apresurarse. Hay que tener cuidado con lo que se compra, con lo que se lee y con lo que se cita. Todo boom pasa de moda. Al pasar la moda hay dos opciones: se ha formado una cultura dominante (mainstream) o se desaparece ${ }^{66}$. Antes de formular juicios categóricos, es razonable esperar que el tiempo pase y ver quiénes (qué trabajos) resisten su paso y quedan en pie dentro de las comunidades jurídicas de nuestros países (hablo de y para Latinoamérica). Es prudente observar qué sucede con las ventas de libros. ¿Trotta lanzará una quinta o una sexta edición de La prueba de los hechos de Michele Taruffo? ¿Con el tiempo, la traducción de Analysis of evidence modificará el panorama de la enseñanza del derecho probatorio en Latinoamérica? Si hechos como estos ocurren,

62 La editorial clasificó este libro como Derecho Procesal: derecho probatorio.

${ }^{63}$ La editorial clasificó este libro como Filosofía del Derecho.

${ }^{64}$ Hay que notar que las materias IBIC de este libro, según la información suministrada por la editorial es: Derecho y procedimiento penal, Filosofía del Derecho y Filosofía: epistemología y teoría del conocimiento.

${ }^{65}$ Las frases corresponden a John Thompson y a Gary Stark y la referencia a Jano es de Baskhar. Todos están citados por Baskhar, M., La máquina de contenido, Fondo de Cultura Económica, 2014, p. xvii.

${ }^{66}$ Martel, F., Cultura Mainstream. Cómo nacen los fenómenos de masas, Madrid: Taurus, 2011. 
es seguro que editores como Marcial Pons y otras pequeñas editoriales latinoamericanas seguirán apostando por el discurso probatorio como un producto cultural; el boom continuará por algunos años más.

El mercado editorial es solo una de las variables a considerar. Hay que observar también qué ocurre con las fuentes del derecho. Si el boom se transforma en derecho legislado en algunos países de nuestra región hay que ver cómo el legislador usa o (re)interpreta las nociones construidas por el boom. Si, en cambio, el boom solo influye en los sistemas jurídicos mediante la jurisprudencia y la doctrina es necesario saber cómo los jueces y los dogmáticos usan y/o (re)interpretan estas nociones para crear derecho de manera extralegislativa.

Ahora bien, si se acepta que hay un boom vale la pena intentar posicionar el trabajo de Coloma en ese boom. El trabajo de Coloma desde principios de la década del 2000 en materia de prueba de los hechos es periférico. Coloma participa desde lejos del ruidoso desarrollo del auge por la investigación sobre la prueba. La periferia es un rasgo geográfico, conceptual, metodológico y estilístico. La periferia geográfica es un hecho: el autor trabaja desde Chile y no desde Europa o Estados Unidos.

La periferia conceptual, metodológica y estilística son decisiones autorales. La red conceptual y el método usados por los trabajos de Coloma solo participan y se yuxtaponen por fragmentos a las nociones y métodos que son de uso corriente en la literatura del boom. Coloma es menos analítico, es decir, sigue menos de cerca las convenciones de los defensores de la filosofía analítica; su forma de trabajo es más tópica y mucho más narrativa; su modo de usar la terminología de la filosofía de la ciencia es más desencantada; tiene menos fe en el potencial explicativo y/o justificativo del léxico proveniente de la filosofía de la ciencia. Finalmente, su estilo de escritura es más literario y fácil de leer para el lego en filosofía. A mi juicio, el trabajo de Coloma que usted puede leer en esta revista participa de estas cualidades. 


\section{Palabras de cierre}

Cuando imagino a los jueces en tanto lectores de varios de los textos que han sido publicados en el marco del boom del discurso probatorio se me viene a la cabeza el pobre hombre rico de $\operatorname{Loos}^{67}$. A principios del siglo XX, el arquitecto austriaco Adolf Loos escribió una breve fábula sobre un pobre hombre rico que quería vivir en una vivienda diseñada hasta el más mínimo detalle por un arquitecto. La completitud de la obra llegó a tal extremo, que en un momento el arquitecto reconviene a su mandante, porque se había puesto las pantuflas (también diseñadas por el arquitecto) en la sala y no en el dormitorio. E1 color de los calcetines destruía la armonía de la sala. Al final, el dueño de la casa no puede recibir ningún regalo, porque todos destruyen la casa y se siente extraño, avergonzado y muerto en su propia casa. Creo que una buena parte de los escritores del boom tienen pretensiones similares a las que inspiraban al arquitecto de la fábula; pretenden diseñar modelos y conceptos tan finos y detallados que impiden hacer con ellos lo más básico: usarlos. En este sentido, el trabajo de Coloma parece ser más usable por los operadores del sistema jurídico que las investigaciones de algunos de los miembros del boom.

Casi lo olvidaba. Si usted, querido lector, acepta que hay un boom de investigaciones sobre prueba, sospeche de lo que acaba de leer, de la revista que tiene entre sus manos y del próximo libro sobre prueba que las editoriales le querrán vender.

67 Loos, A., "The Poor Little Rich Man (April 26, 1900)", Spoken into the Void: Collected Essays 1897-1900, 1900. Translated by Jane O. Newman and John H. Smith (Cambridge, MA, MIT Press, 1982). 
Los estándares de prueba y el boom editorial del discurso...

\section{Bibliografía}

Baskhar, M., La máquina de contenido, Fondo de Cultura Económica, 2014.

Bayon, J. C., Epistemología, moral y prueba de los hechos: hacia un enfoque no Benthamiano, 2008. Ponencia presentada al XIV Congreso ÍtaloEspañol de Teoría del Derecho celebrado en Girona los días 14 y 15 de noviembre de 2008, p. 10. Disponible en: http://www.udg.edu/ areas/FilosofiadelDret/Noticies/tabid/10083/p/10469/language/ es-ES/Default.aspx].

Bloom, H., El canon occidental, Barcelona: Anagrama, 1995.

Bloor, D., Knowledge and social imaginery, Londres: Routledge and Kegan, Paul, 1976.

Bloor, D., "The strengths of the strong program", Philosophy of the social sciences, II (2), 1981, pp. 199-213.

Bourdieu, P., La distinción, Madrid: Taurus, 2012.

Chang, H., Inventing temperature. Measurement and scientific progress, Londres: Oxford University Press, 2004.

Chiassoni, P., "Las cláusulas generales, entre teoría analítica y dogmática jurídica", Revista de Derecho Privado, Universidad del externado de Colombia, 21, 2011, pp. 89-106.

Dei Vecchi, D., "Tres discusiones acerca de la relación entre prueba y verdad", Discusiones, 13, 2, 2013, pp. 233-264.

Ferrajoli, L., Derecho y razón. Teoría del garantismo penal, (primera edición), Valladolid: Editorial Trotta, 1995.

Ferrer Beltrán. J., "Los estándares de prueba en el proceso penal español". Disponible en: http://www.uv.es/cefd/15/ferrer.pdf

Ferrer Beltrán, J., La valoración racional de la prueba, Barcelona: Marcial Pons, 2007.

González Lagier, D., "Presunción de inocencia, verdad y objetividad", en García Amado, J. A. (coord.), Prueba y razonamiento probatorio en Derecho, Granada, 2014, p. 109 y ss.

Gascón Abellán, M., Los hechos en el derecho. Bases argumentales de la prueba, Barcelona: Marcial Pons, 2004. 
Laudan, L., "Porqué un estándar de prueba subjetivo y ambiguo no es un estándar", Doxa, 28, 2005, pp. 95-113.

Laudan, L., Verdad, error y proceso penal. Un ensayo sobre epistemología jurídica (traducción de Carmen Vázquez y Edgar Aguilera), Madrid: Marcial Pons, 2013.

Loos, A., "The Poor Little Rich Man (April 26, 1900)", Spoken into the Void: Collected Essays 1897-1900, 1900. Translated by Jane O. Newman and John H. Smith (Cambridge, MA, MIT Press, 1982). Malem, J., Error judicial y formación de jueces, Barcelona: Gedisa, 2008.

Martel, F., Cultura Mainstream. Cómo nacen los fenómenos de masas, Madrid: Taurus, 2011.

Meli, D. B., Thinking with Objects: The Transformation of Mechanics in the Seventeenth Century, Baltimore: The Johns Hopkins University Press, 2006.

Mocoroa, J., "Breves comentarios sobre prueba y verdad", Inciso, Revista de investigaciones en Derecho y Ciencias Políticas, 18 (1), 2016. Disponible en: http://revistas.ugca.edu.co/index.php/inciso/article/ view/469/903.

Perfecto Ibáñez, A., "Acerca de la motivación de los hechos en la sentencia penal", Doxa, 12, 1992, pp. 257-299. 